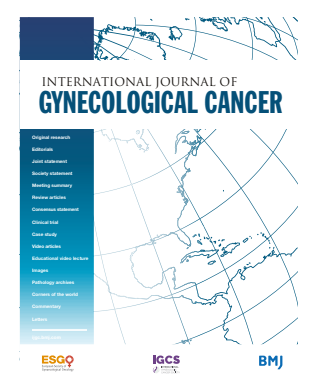

\title{
Transvaginal natural orifice transluminal endoscopic surgery (VNOTES) total retroperitoneal sentinel lymph node biopsy for an endometrial cancer patient with prior colon cancer surgery
}

Cihan Comba (D) , ${ }^{1}$ Gokhan Demirayak, ${ }^{2}$ Cigdem Simsek, ${ }^{1}$ Busra Seker Atas, ${ }^{1}$ İsa Aykut Özdemir ${ }^{3}$

${ }^{1}$ Gynecologic Oncology, Sultangazi Haseki Training and Research Hospital, University of Health Sciences, Istanbul, Turkey

${ }^{2}$ Gynecologic Oncology, Health Science University, Bakırkoy Dr Sadi Konuk Education and Research Hospital, Istanbul, Turkey

${ }^{3}$ Gynecologic Oncology, Istanbul Medipol University, Istanbul, Turkey

\section{Correspondence to} Dr Cihan Comba, Gynecologic Oncology, Sultangazi Haseki Training and Research Hospital, University of Health Sciences, Istanbul 34000, Turkey; comba. cihan@yahoo.com.tr

Accepted 29 July 2021 Published Online First 11 August 2021
(D) Check for updates

(c) IGCS and ESGO 2021. No commercial re-use. See rights and permissions. Published by BMJ.

\begin{tabular}{l}
\hline To cite: Comba C, \\
Demirayak G, Simsek C, \\
et al. Int J Gynecol Cancer \\
2021;31:1386-1387.
\end{tabular}

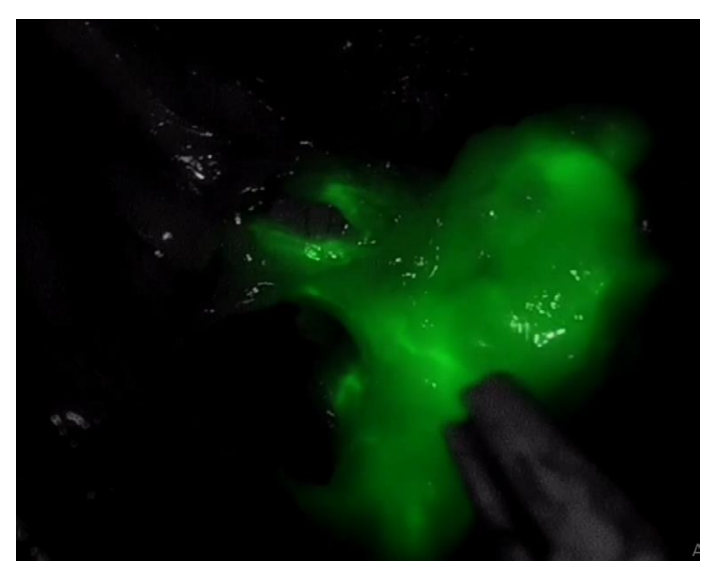

Figure 1 Sentinel lymph node. INTERNATIONAL JOURNAL OF

Istanbul Sultangazi Haseki Training and Research Hospital

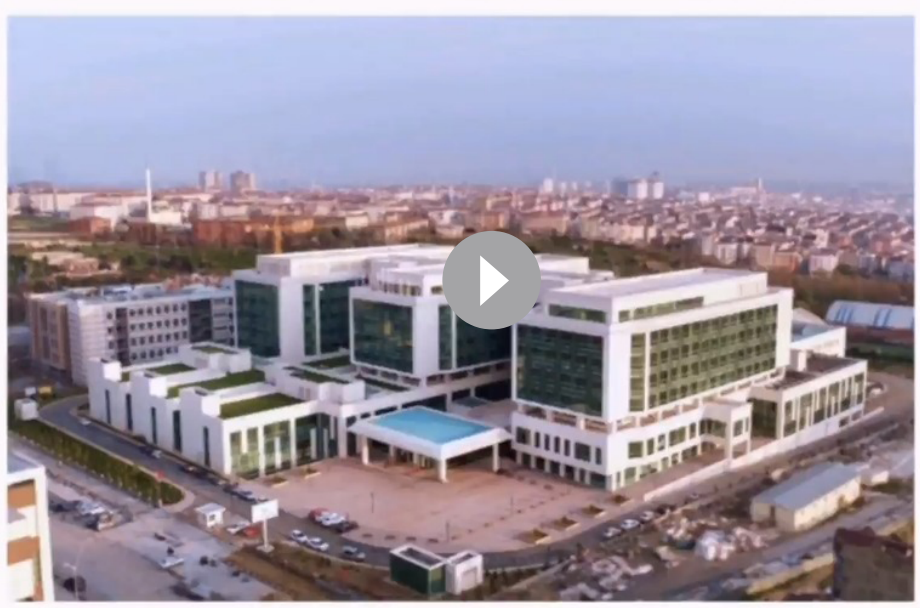

@IJGConline
Endometrial cancer (EC) is the most common gynecological malignancy. Although EC is surgically staged, sentinel lymph node biopsy has become more widely used and has been featured in recently published guidelines for EC. ${ }^{1}$

Randomized trials have shown that minimally invasive approaches to EC staging, laparoscopicassisted vaginal hysterectomy, total laparoscopic hysterectomy, or transvaginal natural orifice transluminal endoscopic surgery (VNOTES) result in lower rates of peri- and post-operative complications than laparotomy, without negatively impacting oncological outcomes. Furthermore, researchers have reported results from vNOTES procedures comparable to those of laparoscopic procedures for benign gynecological conditions in terms of operation times, length of stay 
and estimated blood loss, intra- and post-operative complications, re-admission, pain scores 24 hours post-operatively, and changes in hemoglobin on post-operative day $1 .^{23}$

A 46-year-old woman with gravidity 2 , parity 2 , and body mass index $27.4 \mathrm{~kg} / \mathrm{m}^{2}$ presented with complaints of abnormal uterine bleeding. Endometrial endometrioid type International Federation of Gynecology and Obstetrics (FIGO) grade 2 cancer was detected on endometrial biopsy. The patient had undergone right hemicolectomy with a midline incision for colon adenocarcinoma in 2013, and had received 12 cycles of chemotherapy. There was no other surgery or disease in the patient's history. Sliding viscera was not observed. vNOTES total retroperitoneal bilateral sentinel lymph node biopsy and hysterectomy + bilateral salpingo-0ophorectomy were performed (Figure 1). The operative time for the procedure was 3 hours and the estimated blood loss was $20 \mathrm{~mL}$ (Video 1).

No major complications occurred during the surgery. The patient stayed in hospital for 1 day and no post-operative complications occurred. The final pathology result showed a FIGO grade 2, $3 \times 2 \mathrm{~cm}$ tumorous mass invading less than one-half of the myometrium with right sentinel lymph node macro-metastasis. Adjuvant chemo-radiotherapy was scheduled.

Baekelandt first defined the procedure to remove sentinel lymph nodes in endometrial cancer in a patient who had not previously undergone surgery or experienced bowel adhesions. ${ }^{4}$ Leblanc et al described transvaginal and transperitoneal sentinel lymph node biopsy and pelvic lymph node dissection in an elderly obese patient with endometrial carcinoma. ${ }^{5}$ vNOTES pelvic lymph adenectomy can be performed using conventional laparoscopic instruments. ${ }^{6} \mathrm{~A}$ retrospective study from China showed that the vNOTES procedure is feasible, with a potentially shorter post-operative hospital stay, faster recovery, and better cosmetic results in patients with endometrial cancer. $^{7}$

The retroperitoneal vNOTES procedure has the advantage that it can be used in patients with endometrial cancer to avoid bowel injury during entrance to the abdominal cavity, both in patients with a previous midline incision and in those undergoing first surgery. The difficulty of correctly getting within the bilateral retroperitoneal spaces was the factor determining the appropriate site of vaginal incision, use of blunt dissections to reach the obturator fossa, and placement of the device. The materials used were a transvaginal access platform, advance bipolar sealing device, monopolar cautery, grasping forceps, and indocyanine green.
Although the vNOTES procedure is an applicable procedure with several potential advantages, there is a need for further research of vNOTES sentinel lymph node biopsy to validate its broader clinical usage.

Contributors CC: performed the operation, conceptualized and designed the study, collected data, and drafted the initial manuscript. GD: performed the operation, conceptualized and designed the study, and edited the video. CS performed the operation. BSA: performed the operation. İÄ: performed the operation, conceptualized and designed the study.

Funding The authors have not declared a specific grant for this research from any funding agency in the public, commercial or not-for-profit sectors.

Competing interests None declared.

Patient consent for publication Not required.

Provenance and peer review Not commissioned; externally peer reviewed.

Data availability statement All data relevant to the study are included in the article.

\section{ORCID iD}

Cihan Comba http://orcid.org/0000-0002-3161-2689

\section{REFERENCES}

1 Concin N, Matias-Guiu X, Vergote I, et al. ESGO/ESTRO/ESP guidelines for the management of patients with endometrial carcinoma. Int J Gynecol Cancer 2021;31:12-39.

2 Badiglian-Filho L, Chaves Faloppa C, Narciso de Oliveira Menezes A, et al. Vaginally assisted NOTES hysterectomy with adnexectomy (vNOTES) compared with conventional laparoscopy. A retrospective observational cohort study. Int J Gynaecol Obstet 2021;153. doi:10.1002/ijgo.13483

3 Housmans S, Noori N, Kapurubandara S, et al. Systematic review and meta-analysis on hysterectomy by vaginal natural orifice transluminal endoscopic surgery (vNOTES) compared to laparoscopic hysterectomy for benign indications. J Clin Med 2020;9. doi:10.3390/ jcm9123959. [Epub ahead of print: 07 Dec 2020].

4 Baekelandt JF. New retroperitoneal transvaginal natural orifice transluminal endoscopic surgery approach to sentinel node for endometrial cancer: a demonstration video. J Minim Invasive Gynecol 2019;26:1231-2.

5 Leblanc E, Narducci F, Bresson L, et al. Fluorescence-assisted sentinel (SND) and pelvic node dissections by single-port transvaginal laparoscopic surgery, for the management of an endometrial carcinoma (EC) in an elderly obese patient. Gynecol Oncol 2016;143:686-7.

6 Oh SH, Park SJ, Lee EJ, et al. Pelvic lymphadenectomy by vaginal natural orifice transluminal endoscopic surgery (VNOTES) for earlystage endometrial cancer. Gynecol Oncol 2019;153:211-2.

7 Wang Y, Deng L, Tang S, et al. vNOTES hysterectomy with sentinel lymph node mapping for endometrial cancer: description of technique and perioperative outcomes. J Minim Invasive Gynecol 2021;28:1254-61. 